\title{
A Comparison of Implicit Memory Tests in Schizophrenic Patients and Normal Controls
}

\author{
María José Soler ${ }^{1}$, Juan Carlos Ruiz ${ }^{1}$, Inmaculada Fuentes ${ }^{1}$, and Pilar Tomás ${ }^{2}$ \\ ${ }^{1}$ Universitat de València \\ ${ }^{2}$ Centro de Rehabilitación e Inserción Social de Enfermos Mentales de Velluters. Conselleria \\ de Bienestar Social de la Generalitat Valenciana y Eulen Servicios Sociosanitarios
}

\begin{abstract}
The objective of the current study was to compare the performance of schizophrenic patients and normal controls on implicit memory tests. Two neuropsychological tasks were administered to 29 patients and normal participant samples. The implicit tests were: Word fragment completion and Word production from semantic categories. The priming score was the variable of interest. Priming effects are obtained in normal subjects and schizophrenia patients, regardless of the implicit test used. However, a dissociation in priming between normal and patient groups was observed, depending on the test used. For word fragment test, priming was identical between the two groups. However, for word production, priming obtained in schizophrenics was lower than priming in normal controls. Results confirm a dissociation effect in implicit memory tests. These results could be explained in the context of the Roediger and Blaxton (1987) distinction between data-driven and conceptually-driven processing. This evidence suggests that a complete neuropsychological assessment of memory in schizophrenia should include different kinds of implicit memory tests (procedural, perceptual, and conceptual tasks).

Keywords: priming, implicit memory, schizophrenia, memory impairment
\end{abstract}

\begin{abstract}
El objetivo de este estudio fue comparar la ejecución de pacientes esquizofrénicos y controles no clínicos en tests de memoria implícita. Se administraron dos pruebas neuropsicológicas a una muestra de 29 pacientes y a dos muestras de participantes no clínicos. Los tests implícitos fueron: Completar fragmentos de palabras y Generación de ejemplares de categorías semánticas. La variable de interés fue la facilitación. Los efectos de facilitación se obtienen en sujetos no clínicos y en pacientes esquizofrénicos, independientemente del test implícito que se utilice. Sin embargo, se ha observado una disociación en la facilitación entre grupos de controles y pacientes, dependiendo del test utilizado. En tests de fragmentos de palabras la facilitación es idéntica en los dos grupos. Sin embargo, en producción de palabras, la facilitación obtenida en esquizofrénicos es menor que la facilitación en controles. Los resultados confirman la existencia de un efecto disociativo en tests de memoria implícita. Estos resultados podrían explicarse en el contexto de la distinción de Roediger y Blaxton (1987) entre procesamiento guiado por los datos y procesamiento guiado conceptualmente. Esta evidencia sugiere que la evaluación neuropsicológica de la memoria en la esquizofrenia debería incluir distintos tipos de pruebas de memoria implícita (procedimentales, perceptuales, y conceptuales).

Palabras clave: facilitación, memoria implícita, esquizofrenia, daños en memoria
\end{abstract}

This study was supported by a research grant of the Spanish Ministry of Education and Science (SEJ2006-07055).

Correspondence concerning this article should be addressed to María José Soler, Departamento de Psicología Básica., Universidad de Valencia, Avda. Blasco Ibáñez, 21, 46010 - Valencia (Spain). E-mail: Maria.J.Soler@uv.es 
In recent years, neuropsychological research on schizophrenia has shown interest in implicit memory in order to investigate whether nonconscious forms of memory are impaired or preserved in these patients. Implicit memory has been studied using the basic experimental phenomenon called "priming" (Graf \& Schacter, 1985). Briefly, Roediger (1990) defined priming as the "transfer from past experience on tasks that do not require conscious recollection of recent experiences for their performance."

Experimental priming has been studied with implicit memory tests. In a typical implicit memory test, there are two phases: first, subjects have to process a stimulus (called a "prime") (e.g., to judge the familiarity of a list of words using a scale); second, subjects are told to perform a task (e.g., to complete word fragments) without reference to the first phase of the test. In implicit tests, subjects are unaware of the purpose of the primes, because the causal role of the priming stimulus is implicit, in the sense that its effect is not mediated by conscious recollection.

Currently, there are many implicit tests used to elicit nonconscious memory. In a recent review, Toth (2000) proposes a classification that includes most of the implicit tests available. This classification is based on a distinction among perceptual, conceptual, and procedural tests. Perceptual tests, such as word fragment completion or lexical decision, require subjects to process a stimulus focus based on its superficial characteristics, producing some changes in the subject's perceptual system. Conceptual tests, such as category-instance (exemplar) generation or fact (general knowledge) generation, use retrieval cues as category labels to elicit responses that are meaningfully related to these cues. Procedural tests, such as pursuit rotor or tower of Hanoi, require subjects to perform extended sensory, motor, or cognitive tasks, like when learning a new perceptual motor skill.

Research on implicit memory with schizophrenic patients has used procedural, perceptual, and conceptual tests to show a pattern of dissociations between episodic long- or short-term memory and implicit memory (McKenna, Ornestein, \& Baddeley, 2002).

For example, different studies of schizophrenic patients' performance on procedural tests, such as the pursuit rotor, have obtained results showing that schizophrenics acquire this motor skill at a rate similar to normal controls, but the patients show a significantly poorer episodic memory performance (Goldberg et al., 1993; Granholm, Bartzokis, Asarnow, \& Marder, 1993).

Priming has also been obtained in schizophrenia with a variety of other procedural tests, such as serial reaction time, where the subjects press one of four keys corresponding to stimuli that appears in one (of four) positions on a screen (Green, Kern, \& Williams, 1997); or on a probabilistic classification task, in which subjects decide whether a set of four geometrical shapes are predictive of hypothetical weather conditions of rain or sunshine (Keri et al., 2000). All these studies found a dissociation effect. Implicit memory was preserved, although performance in schizophrenics was poorer than performance in normal controls.

A dissociation effect between explicit and implicit memory has been also found in patients with schizophrenia, using conceptual tests. In an experiment that compared schizophrenics' performance on an explicit memory test (word recall cued by semantic categories) and an implicit memory test (semantic category-exemplar generation), Schwartz, Rosse, and Deutsch (1993) found that normal and patient groups obtained similar priming, but both groups were significantly different on word recall.

Finally, when perceptual tests such as word-stem completion are used to study implicit memory in schizophrenic patients, results confirm the pattern of explicitimplicit dissociations. Patients with schizophrenia usually show preserved priming (Brebion, Amador, Smith, \& Gorman, 1997; Kazes et al., 1999) and impaired explicit memory (using free recall tasks).

More recently, a number of studies have provided results that support "the view that implicit memory is not unitary and can be fractionated like episodic or explicit memory tasks" (Wilson \& Zangwill, 2002). For example, Reber and Squire (1999) demonstrated that Parkinson's disease patients generally perform like normal subjects on some implicit memory tests, except skill learning tasks. Wilson, Alderman, and Burgess (1998) also showed dissociations among people with amnesia and control subjects in a fragmented picture task and in an auditory priming task.

According to Roediger and Blaxton (1987), implicit memory tests themselves can be dissociated because there are obvious differences in task demands posed by different kinds of tests. Dissociations between implicit memory tests can be accounted for by postulating a continuum of tests, going from those requiring more perceptual information (data-driven tests) to those requiring knowledge of meaning (conceptually-driven tests).

However, while these dissociations have been studied in some clinical populations, it is rare to find an investigation that studies the pattern of differences between implicit memory tests in patients with schizophrenia.

The main objective of the present investigation was to better characterize the implicit memory profile of schizophrenic patients, comparing patients' performance and normal controls' performance on two implicit tests. The present study assesses implicit memory using word fragment completion and word production from semantic categories tests. Word fragment is a prototypical perceptual test that requires the processing of mostly perceptual characteristics of information, whereas word production from semantic categories is a prototypical conceptual test that is more meaning demanding and requires more conceptually elaborated processing.

Based upon previous research, we hypothesized that schizophrenia patients would show priming on the word fragment completion and on the word production tests. However, we further hypothesized a dissociation effect in 
the magnitude of priming between normal comparison subjects and patients. We can expect no differences on magnitude of priming in word completion, whereas these differences would appear in word production from semantic categories. This pattern of results would support the contention that schizophrenia patients have memory impairments in global verbal memory tasks based on semantic organization of the material, as is well illustrated in a recent meta-analysis of 204 studies carried out between 1980 and 1997 and collected by Heinrichs and Zakzanis (1998).

\section{Method}

\section{Participants}

Twenty-nine schizophrenic outpatients (26 males and 3 females) were included in this study. The diagnosis of schizophrenia was made according to the Diagnostic and Statistical Manual of Mental Disorders ( $4^{\text {th }}$ ed., American Psychiatric Association, 1994) criteria. The mean age for the group was 37.9 years. The mean number of years of full-time education was 7.79. The mean time since first symptoms was 17.5 years. Mean global IQ derived from the short form (Blyler, Gold, Iannone, \& Buchana, 2000) of the Wechsler Adults Intelligence Scale -WAIS-III(Wechsler, 1999) scores was $85.89(S D=16.27)$.

Four of schizophrenic patients received typical antipsychotics, 11 of the schizophrenic patients received atypical antipsychotics, and 14 of schizophrenic patients received both antipsychotic medications.

The patients were evaluated on the Rivermead Behavioural Memory Test (RBMT; Wilson, Cockburn, Baddeley, \& Hiorns, 1989) which is a test battery for detecting and monitoring everyday memory problems. The mean screen total was 8.55 (range 7-12), which indicates a memory impairment.

From previous experiments with word fragment completion and category production tests, we selected two groups of subjects from the University of Valencia at Spain, who received extra course credit. None of these subjects had history of any head injury or major psychiatric disturbance. Thirty-four subjects were selected for comparison on the word fragment completion test. A separate sample of thirty-nine was selected for the word production from semantic categories test. Although the use of these two groups as archival normal comparison participants could be considered a limitation of this study, the procedure is not new (e.g., Hofer et al., 2006).

\section{Material and Procedure}

Participants were administered two implicit memory tests: the word fragment completion test and the word production from semantic categories test.
For the word fragment completion test, 56 word fragments were selected from the Dasi, Soler and Ruiz (2004) norms. This database includes normative information on word frequency and completion difficulty of 196 Spanish word fragments with a single solution. The 56 word fragments selected for the experiment had a moderate difficulty level of completion (mean of 0.40). Of the 56 word fragments, 28 corresponded to high frequency words (frequency mean of 62 per million), and the other 28 corresponded to low frequency words (frequency mean of 4 per million).

In the first phase of the test, subjects were required to judge the familiarity of 28 words on a scale ranging from 1 (extremely unfamiliar) to 7 (extremely familiar) on a rating sheet, to ensure that participants attended to the word. Next, and for five minutes, subjects were given a filler task (subjects wrote the name of Spanish cities). After the filler task, participants were asked to complete 56 word fragments. Word fragments were presented for $12 \mathrm{~s}$ each, in lowercase letters, with missing letters replaced by underscores. Subjects had to write the first word that came to mind that successfully completed the fragment. No explicit reference was made to the rated list. Twenty-eight of the word fragments could be completed with words from the rated list (studied word fragments), and the remaining 28 word fragments could be completed with words that were frequency-matched with the words on the rated list (nonstudied word fragments).

The variable of interest was the proportion of fragments correctly completed. The priming score was obtained by subtracting the proportion of studied word fragments correctly completed from the proportion of nonstudied word fragments correctly completed.

For the word production from semantic categories test, 40 exemplars extracted from 40 category names were selected from Pascual and Musitu (1980) norms. This database includes the probability of generation of exemplars within each category. The 40 exemplars selected in the experiment ("expected exemplars") had a low probability of generation (mean of 0.17). They are between the 14 and 17 frequency rank position in the norms (for example, in the "color" category, we choose the exemplar "purple" because this item is in this rank).

In the first phase of the word production test, subjects were required to perform a rating task similar to the one used for word fragment completion. Participants were shown 28 category exemplars (study list) and asked to rate how familiar or unfamiliar they were.

After a filler task (for five minutes), participants were asked to give as many exemplars as possible from 40 category names presented one at a time for $12 \mathrm{~s}$ each. Twenty-eight of the category names were represented by an exemplar in the study list ("old" category), and the other 12 were completely new in the experiment ("new" category). Subjects were simply instructed to write as many exemplars as possible from each category. No explicit reference was made to the rated list. 
The variable of interest was the proportion of "expected exemplars" from each category. The priming score was obtained by subtracting the proportion of expected exemplars produced from old category names from the proportion of expected exemplars produced from new category names.

\section{Results}

Results were analyzed using SPSS, version 11. Differences between the two groups (schizophrenic patients and normal comparison subjects) on performance and priming scores were assessed using analysis of variance (ANOVA).

\section{Word Fragment Completion Test}

In order to assess implicit memory, the proportion of fragments correctly completed for studied and nonstudied word fragments and priming scores by group was calculated (Table 1). A Group $\times$ Study Condition ANOVA indicated that there was a significant group effect, $F(1,61)=5.15, p$ $=.03, \eta^{2}=0.94,1-\beta=1.00$, and a significant study condition effect $F(1,61)=279.93, p=.001, \eta^{2}=0.82,1-$ $\beta=1.00$. A simple effects test performed on the interaction indicated that significantly more studied word fragments were completed compared to nonstudied word fragments in the patient group, $F(1,28)=107.73, p=.001, \eta^{2}=0.79$, $1-\beta=1.00$, and in the normal comparison group, $F(1,33)$ $=181.15, p=.001, \eta^{2}=0.85,1-\beta=1.00$. Therefore, both groups showed a significant priming or implicit memory.

To compare priming between the two groups, a one-way ANOVA was performed. There was no significant effect of group, $F(1,61)=0.51, p=.48, \eta^{2}=0.01,1-\eta=0.11$. Priming obtained in schizophrenic patients $(M=0.28)$ and priming obtained in normal comparison subjects $(M=0.30)$ was statistically identical.

\section{Word Production from Semantic Categories Test}

The analysis performed on the word fragment completion scores was repeated for the scores obtained on the word production test (Table 2).

The Group $\times$ Study Condition ANOVA indicated that there was a significant group effect $F(1,66)=19.34, p=$ $.01, \eta^{2}=0.23,1-\beta=0.99$, and a significant study condition effect, $F(1,66)=122.47, p=.001, \eta^{2}=0.65,1-\beta=1.00$. A simple effects test performed on the interaction indicated that significantly more exemplars from old categories were produced compared to exemplars from new categories in the patient group, $\mathrm{F}(1,28)=30.55, p=.001, \eta^{2}=0.52,1-$ $\beta=1.00$, and in the normal comparison group, $F(1,38)=$ $109.68, p=.001, \eta^{2}=0.74,1-\beta=1.00$. As on the word fragment completion test, both groups showed significant priming or implicit memory.

A one-way ANOVA was performed to compare priming between the two groups. There was a significant effect of group, $F(1,66)=11.22, p=.001, \eta^{2}=0.15,1-\beta=0.91$. Priming obtained in patients with schizophrenia $(M=0.08)$ was significantly lower than the priming obtained in normal comparison subjects $(M=0.16)$.

Overall, both groups showed implicit memory, although there is a dissociation effect between the tests. There were no priming differences between groups on the word fragment completion test, but there were significant differences on the word production from semantic categories test.

\section{Discussion}

The results of present study confirm the general view of preserved implicit memory in patients with schizophrenia (McKenna, Ornstein, \& Baddeley, 2002). Priming is found in patients and in normal comparison

Table 1

Mean Proportion and Standard Deviation (in Brackets) of Fragments Correctly Completed for Studied and Nonstudied Fragments and Priming Scores by Group in the Word Fragment Completion Test

\begin{tabular}{lccr}
\hline Group & Studied word fragments & Nonstudied word fragments & Priming \\
\hline Schizophrenics $(n=29)$ & $.55(.20)$ & $.27(.13)$ & $.28(.14)$ \\
Controls $(n=34)$ & $.62(.09)$ & $.32(.11)$ & $.30(.13)$ \\
\hline
\end{tabular}

Table 2

Mean Proportion and Standard Deviation (in Brackets) of Expected Exemplars Produced from Old and New Categories and Priming by Group in the Word Production from Semantic Categories Test

\begin{tabular}{lccr}
\hline GroupGroup & Exemplars from "old" categories & Exemplars from "new" categories & Priming \\
\hline Schizophrenics $(n=29)$ & $.10(.08)$ & $.01(.03)$ & $.09(.08)$ \\
Controls $(n=34)$ & $.20(.10)$ & $.04(.08)$ & $.16(.09)$ \\
\hline
\end{tabular}


subjects on both implicit tests (word completion and word production tasks). However, the results also show that patients with schizophrenia have a significantly poorer global performance than normal comparison subjects on these tests. As can be seen from Table 1, the mean proportion of fragments correctly completed by patients on the word fragment completion test was lower than the mean proportion in normal comparison participants. An identical result was also obtained on the word production test (Table 2). These findings are in accordance with previous studies that compare the performance of schizophrenic patients and controls on other implicit and procedural memory tasks (Clare, McKenna, Mortimer, \& Baddeley, 1993; Schwartz, Rosse, Veazey, \& Deutsch, 1996; Sponheim, Steele, \& McGuire, 2004). According to McKenna et al. (2002) a possible explanation of this pattern of findings is that the poor overall performance reflects the schizophrenic tendency to general intellectual impairment. In the present study, general intellectual function was assessed by means of Wais-III. The IQ testing revealed that schizophrenic patients have a mean score of 85.89, within 1 standard deviation of the population mean. This mean score was similar to other previous studies with schizophrenic patients (e.g., Gold, Randolph, \& Carpenter, 1992). However, our results also confirm an important finding. Intellectual function can be impaired while other cognitive functions, in this case implicit memory, are preserved.

The second focus of interest in the present study was to examine whether performance on word fragment and word production tests can be dissociated. Our data indicated that the type of implicit test produces a dissociation effect on the magnitude of priming, showing a different pattern of results in patient and normal comparison groups. In THE word fragment completion test, patient and normal comparison subjects obtained an equal value of priming. However, in the word production test, the magnitude of priming was significantly greater in normal subjects than in schizophrenics.

This difference in the magnitude of the priming produced by type of implicit task is important because it goes against the traditional view that implicit memory is a single entity with a single underlying pathology. Probably, priming involves different mechanisms in word fragment and word production tests, so the difference observed in priming could be explained by the type of processes evoked on both tasks.

The data-driven and conceptually-driven tests distinction formulated by Roediger, Srinivas, and Weldon (1989) may provide a possible theoretical explanation for the dissociation effect.

Word fragment completion is a data-driven task in which the fragments evoke the perceptual identification record of the target. In this test, the stimulus presented during the study phase is shown on the test in a perceptually related form, although partially. The letters in the fragment, drawn randomly from the word, are poor cues for locating words in the lexicon. Thus, perceptual overlap between study and test stimuli is sufficient to produce priming (Fay, Isingrini, $\&$ Clarys, 2005). Our data show equal priming in normal comparison subjects and patients with schizophrenia (see the meta-analysis of implicit memory tasks with nonclinical populations of Light, Prull, La Voie, \& Healy, 2000), which suggests that perceptual comparison processes are apparently not affected by the cognitive deficits of schizophrenia.

On the other hand, word production from semantic categories is a conceptually-driven task in which the provided information in the test phase is semantically related to the studied information, and requires a response based on stimulus meaning.

The characteristics of semantic processing in schizophrenia have been studied in several investigations (Aleman, Hijman, de Haan, \& Kahn, 1999; Duffy \& O'Carroll, 1994; Elvevag, Weinstock, Akil, Kleinman, \& Goldberg, 2001). Many of these studies examined word meaning, categorization, and the relationship between concepts using some explicit tests such as free and cued recall, verbal fluency tests such as word categorization and vocabulary, and semantic processing tests such as speed of verification. These investigations have reported that performance of patients with schizophrenia is impaired.

Our data show that the patients' group obtains priming on the word production test, however, their performance reveals significantly less priming than the comparison normal group. Probably, the underlying mnemonic processes in conceptually-driven tests such as word production are similar to those in some explicit tests (e.g., free recall, word categorization, or vocabulary). All these tests seem to involve an elaborative processing that is predominantly conceptual, and, therefore, would be more affected by the cognitive deficits present in schizophrenia.

The general disturbance of semantic memory is, at this moment, an intriguing aspect of schizophrenia memory impairment, and some recent studies suggest that semantic processing abnormalities could be associated with thought disorder in schizophrenia (Rossells, Shapleske, \& David, 1998). Further investigations should focus on the nonconscious aspects of semantic processing, which could help to advance our understanding of the relations between thought and semantic memory deficits in schizophrenia, and what should be the targets in rehabilitation.

Thus, the findings of our study are of particular significance to characterize memory dysfunction in patients with schizophrenia because they confirm that implicit memory does not seem to be a unitary concept. The evidence that there is a dissociation effect in implicit memory tests means that a complete neuropsychological assessment of memory impairment in schizophrenia should be performed. 


\section{References}

American Psychiatric Association. (1994). Diagnostic and statistical manual of mental disorders ( $4^{\text {th }}$ ed.). Washington, DC: Author.

Aleman, A., Hijman, R., de Haan, E.H.F., \& Kahn, R.S. (1999). Memory impairment in schizophrenia: A meta-analysis. American Journal of Psychiatry, 156, 1358-1366.

Blyler, C.R., Gold, J.M., Iannone, V.N., \& Buchana, R.W. (2000). Short form of the WAIS-III for use with patients with schizophrenia. Schizophrenia Research, 46, 209-215.

Brebion, G., Amador, X., Smith, M.J., \& Gorman, J.M. (1997). Mechanisms underlying memory impairment in schizophrenia. Psychological Medicine, 27, 383-393.

Clare, L., McKenna, P.J., Mortimer, A.M., \& Baddeley, A.D. (1993). Long-term memory in schizophrenia: What is impaired and what is preserved? Neuropsychologia, 31, 1225-1241.

Dasi, C., Soler, M.J., \& Ruiz, J.C. (2004). Normative data on the familiarity and difficulty of 196 Spanish word fragments. Behavior Research Methods, Instruments \& Computers, 36, 559-563.

Duffy, L., \& O'Carroll, R. (1994). Memory impairment in schizophrenia - a comparison with that observed in the alcoholic Korsakoff syndrome. Psychological Medicine, 24, 155-165.

Elvevag, B., Weinstock, D.M., Akil, M., Kleinman, J.E., \& Goldberg, T.E. (2001). A comparison of verbal fluency tasks in schizophrenic patients and normal controls. Schizophrenia Research, 51, 119-126.

Fay, S., Isingrini, M., \& Clarys, D. (2005). Effects of depth-ofprocessing and ageing on word-stem and word-fragment implicit memory tasks: Test of the lexical-processing hypothesis. European Journal of Cognitive Psychology, 17, 785-802.

Gold, J.M., Randolph, C., \& Carpenter, C.J. (1992). The performance of patients with schizophrenia on the Wechsler Memory Scale-Revised. Clinical Neuropsychologist, 6, 367373.

Goldberg, T.E., Torrey, E.F., Gold, J.M., Ragland, J.D., Bigelow, L.B., \& Weinberg, D.R. (1993). Learning and memory in monozygotic twins discordant for schizophrenia. Psychological Medicine, 23, 71-85.

Granholm, E., Bartzokis, G., Asarnow, R.F., \& Marder, S.R. (1993). Preliminary associations between motor and procedural learning, basal ganglia T2 relaxation times, and tardative dyskinesia in schizophrenia. Psychiatry Research: Neuroimaging, 50, 33-44.

Graf, P., \& Schacter, D. (1985). Implicit and explicit memory for new associations in normal and amnesic subjects. Journal of Experimental Psychology: Learning, Memory, and Cognition, 11, 501-518.

Green, M.F., Kern, R.S., \& Williams, O. (1997). Procedural learning in schizophrenia: Evidence from serial reaction. Cognitive Neuropsychiatry, 2, 123-134.

Heinrichs, R.W., \& Zakzanis, K.K. (1998). Neurocognitive deficit in schizophrenia: A quantitative review of the evidence. Neuropsychology, 12, 426-445.
Hofer, A., Baumgartner, S., Bodner, T., Edlinger, M., Hummer, H., Kemmler, G., Rettenbacher, M.A., \& Fleischhacker, W.W. (2006). Patient outcomes in schizophrenia II: The impact of cognition. European Psychiatry, 20, 395-402.

Kazes, M., Berthet, L., Danion, J.M., Amado, I., Willard, D., Robert, P., \& Poirier, M.F. (1999). Impairment of consciously controlled use of memory in schizophrenia. Neuropsychology, 13, 54-61.

Keri, S., Kelemen, O., Szekeres, G., Bagoczky, N., Erdélyi, A., Antal, G., Benedek, G., \& Janka, Z. (2000). Schizophrenics know more than they can tell: Probabilistic classification learning in schizophrenia. Psychological Medicine, 30, 149155.

Light, L.L., Prull, M.W., La Voie, D., \& Healy, M.R. (2000). Dualprocess theories of memory in old age. In T.J. Perfect \& E.A. Taylor (Eds.), Models of cognitive aging (pp. 238-300). Oxford, UK: Oxford University Press.

McKenna, P.J., Ornstein, T., \& Baddeley, A.D. (2002) Schizophrenia. In A.D. Baddeley, M.D. Kopelman, \& B.A. Wilson (Eds.), The handbook of memory disorders (pp. 413435). West Sussex, UK: Wiley \& Sons.

Pascual, J.P., \& Musitu G. (1980). Normas categoriales. Psicológica, $1,157-174$

Reber, P.J., \& Squire, L.R. (1999). Intact learning of artificial grammars and intact category learning by patients with Parkinson's disease. Behaviour Neurosciences, 113, 235-242.

Roediger, H.L. (1990). Implicit memory. Retention without remembering. American Psychologist, 45, 1043-1056.

Roediger, H.L., \& Blaxton, T.A. (1987). Retrieval modes produce dissociations in memory for surface information. In D. Gorfein \& R.R. Hoffman (Eds.), Memory and cognitive processes: The Ebbinghaus Centennial Conference (pp. 349-379). Hillsdale, NJ: Erlbaum.

Roediger, H.L., Srinivas, K., \& Weldon, M.S. (1989). Dissociations between implicit measures of retention. In S. Lewandowsky, J.C. Dunn, \& K.Kirsner (Eds.), Implicit memory: Theoretical issues (pp. 67-84). Hillsdale, NJ: Erlbaum.

Rossells, S.L., Shapleske, J., \& David, A.S. (1998). Sentence verification and delusions: A content-specific deficit. Psychological Medicine, 28, 1189-1198.

Schwartz, B.L., Rosse, R.B., \& Deutsch, S.I. (1993). Limits of the processing view in accounting for dissociations among memory measures in a clinical population. Memory and Cognition, 21, 63-72.

Schwartz, B.L., Rosse, R.B., Veazey, C., \& Deutsch, S.I. (1996). Impaired motor skill learning in schizophrenia: Implications for corticostriatal dysfunction. Biological Psychiatry, 39, 241248.

Sponheim, S.R., Steele, V.R., \& McGuire, K.A. (2004). Verbal memory processes in schizophrenia patients and biological relatives of schizophrenia patients: Intact implicit memory, impaired explicit recollection. Schizophrenia Research, 71, 339-348.

Toth, J.P. (2000). Nonconscious forms of human memory. In E. Tulving \& F.I.M. Craik (Eds.), The Oxford handbook of memory (pp. 245-261). Oxford, UK: Oxford University Press. 
Wechsler, D. (1999). Escala de Inteligencia de Wechsler para Adultos-III. Madrid: TEA Ediciones.

Wilson, B.A., Alderman, N., \& Burgess, P.W. (1998). Behavioural Assessment of the Dysexecutive Syndrome. Bury St. Edmund, UK: Thames Valley Test Co.

Wilson, B.A., Cockburn, J.M., Baddeley A.D., \& Hiorns, R. (1989). The development and validation of a test battery for detecting and monitoring everyday memory problems. Journal of Clinical and Experimental Neuropsychology, 11, 855-870.
Wilson, B.A., \& Zangwill, O. (2002). Assessment of memory disorders. In A.D. Baddeley, M.D. Kopelman, \& B.A. Wilson (Eds.), The handbook of memory disorders. Chichester, UK: Wiley \& Sons.
Received November, 28, 2005

Revision received May, 26, 2007 Accepted June, 6, 2007 